
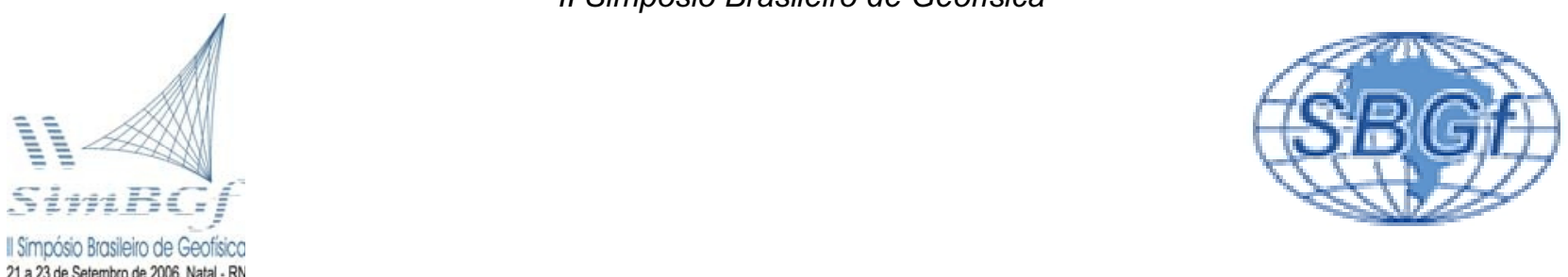

\title{
Mapeamento em subsuperfície da presença de catalisador gasto e da lixiviação de metais para o solo, utilizando a SEVME como ferramenta de prospecção geofísica - Estudo de caso.
}

Pimenta, Vitor B., Soares, Maurício J. S. - BRAIN Tecnologia.

\section{Resumo}

O presente artigo apresenta os resultados da integração das ferramentas geofísica, descrição geológica e geoquímica para a avaliação da presença de resíduo sólido (catalisador gasto) enterrado em subsuperfície e da lixiviação dos metais (presentes neste resíduo) para o solo. Para tal foram utilizadas as técnicas de SEVME (Sondagem Elétrica Vertical Multieletrodo) juntamente com um plano de sondagem, coleta de amostras e análises geoquímicas.

\section{Introdução}

O catalisador gasto é caracterizado como resíduo sólido de origem industrial, resultado do processo de craqueamento catalítico, utilizado na cadeia produtiva do refino do petróleo que gera um material granulado rico em compostos de cobalto, molibdênio, níquel e vanádio, suportados em alumina. De acordo com estudos anteriores (Brain, 2000, 2005 e 2006) o material apresenta características elétricas de baixa resistividade, ou alta condutividade.

A área de estudo localiza-se na porção meridional do Cráton São Francisco, poucos quilômetros a norte da megaestrutura conhecida como Quadrilátero Ferrífero.

Localmente ocorrem rochas de idade arqueana do denominado Complexo Belo Horizonte. As primeiras interpretações geológicas acerca das rochas e estruturas que afloram nos complexos metamórficos da região propuseram como constituídos de granitos I.s. que formam o embasamento do Quadrilátero Ferrífero.

O Depósito de Catalisador Gasto está localizado em um alto topográfico com cotas variando entre 845 e 849 m e, geologicamente, é constituída por um solo residual de rochas do Complexo Belo Horizonte.

Foram identificadas feições de escavações na forma de valas, dentro das quais foram dispostos o catalisador gasto com posterior cobertura por solo de aterro. As

espessuras entre as superfícies dos aterros e os fundos das valas podem atingir a profundidade de $9 \mathrm{~m}$.

\section{Metodologia/ Problema Investigado}

O presente trabalho apresentou as seguintes etapas para a execução do diagnóstico geoambiental:

(1) Levantamento Geofísico constituído pela Sondagem Elétrica Vertical Multieletrodo (SEVME), para avaliação do arcabouço geológico da área e identificação de zonas de anomalias de resistividade;

(2) Duas campanhas de sondagem e geoquímica constituídas pela execução de sondagens a trado, amostragem de solo e análises geoquímicas.

As aquisições geofísicas foram adquiridas valendo-se de um controle topográfico regular por levantamento a estação total.

Foram adquiridas um total de 21 seções de SEVME, obedecendo ao protocolo tipo Wenner, separadas segundo um malha regular de 20 (vinte) metros. A configuração proposta para a área investigada compõese por seções ortogonais de comprimento igual a 188,0 metros, proporcionando uma cobertura suficiente para caracterizar o arcabouço geológico local, incluindo a camada de aterro onde se encontra o depósito de catalisador gasto.

Foram realizadas duas campanhas de sondagem a trado manual em um total de 57 (cinqüenta e sete) furos. A primeira campanha contou com perfurações que atingiram até 10 metros e a segunda 15 metros de profundidade. As sondagens foram distribuídas pela área estudada acompanhando as anomalias detectadas nas interpretações das seções SEVME, tendo como finalidade a descrição geológica-estratigráfica e a coleta de amostras de solo para análises químicas de compostos orgânicos (hidrocarbonetos), inorgânicos (metais).

\section{Resultados}

As seções de SEVME mostram correspondência com o arcabouço geológico da área. Apresentam alta resistividade a profundidade de aproximadamente 25,0 metros representando as rochas frescas do embasamento cristalino, sobreposta pelo manto de intemperismo (resistividade mais baixa) e pela cobertura 
de aterro na qual se insere o catalisador, de características mais condutivas, conforme pode ser visualizado na Figura 1.

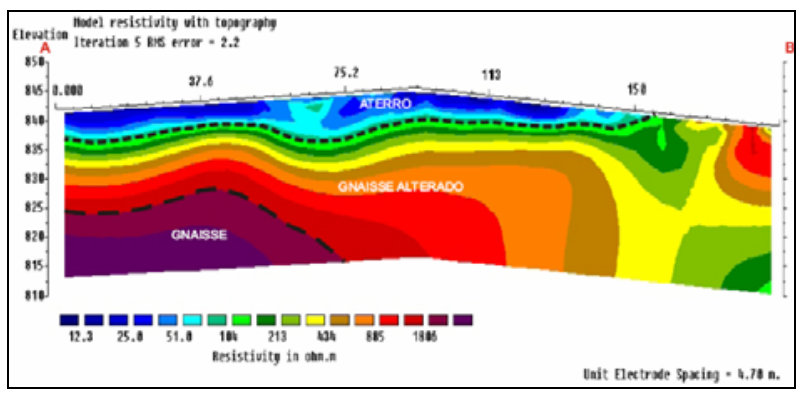

Figura 1: SEVME apresentando as características resistivas do terreno estudado

$\mathrm{Na}$ análise do conjunto das SEVME's procurou-se mapear as zonas de baixa resistividade, possivelmente associadas à presença do catalisador gasto. Durante a análise individual das seções SEVME foram destacadas as zonas de baixa resistividade relativas a cada seção conforme exemplificado na Figura 1.

Foram determinados dois conjuntos de anomalias de baixa resistividade. O primeiro entre o intervalo de 0 e 4,0 metros de profundidade e o segundo, atingindo profundidades de até 20,0 metros. Essas anomalias foram utilizadas para a locação dos furos de sondagens, buscando comprovar a correspondência entre as anomalias geofísicas e possíveis anomalias geoquímicas.

A seção de SEVME da Figura 2 apresenta anomalias pouco profundas de baixa resistividade. A seção de SEVME da Figura 3 apresenta anomalias profundas, atingindo 10 a $20 \mathrm{~m}$ de profundidade na porção central da área investigada.

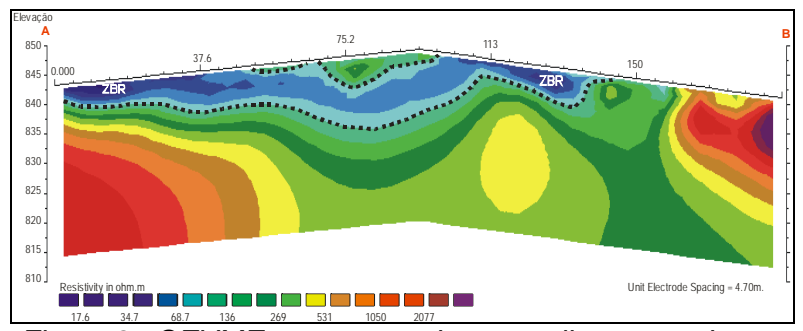

Figura 2: SEVME apresentando anomalias rasas de baixa resistividade

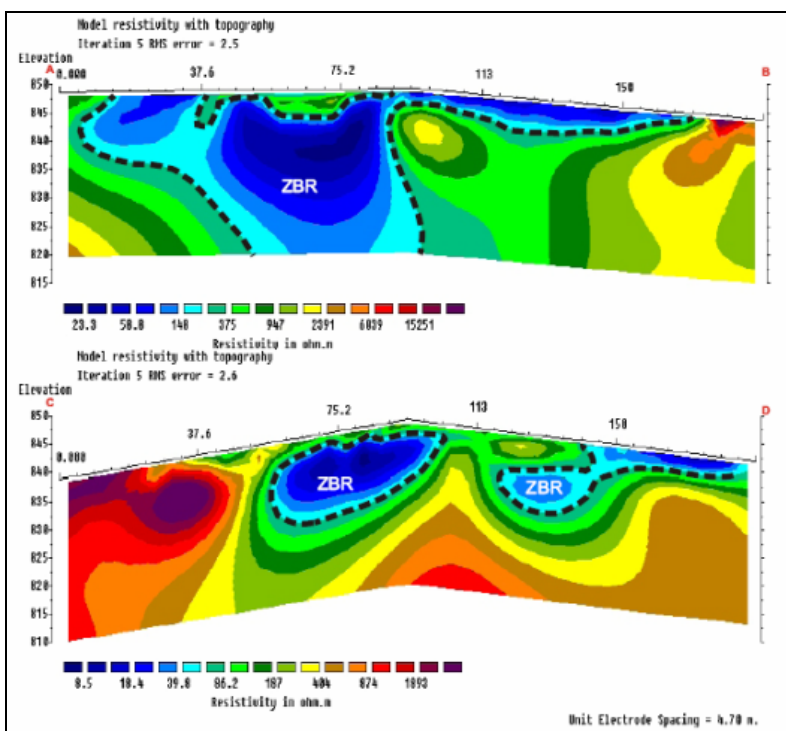

Figura 3: SEVME apresentando anomalias de baixa resistividade profundas.

O conjunto das SEVME's realizadas, Figuras 4 e 5, mostram a configuração tridimensional das anomalias de baixa resistividade, representadas pela cor azul, em estratos mais superficiais na porção norte e atingindo maiores profundidades na porção centro sul da área.

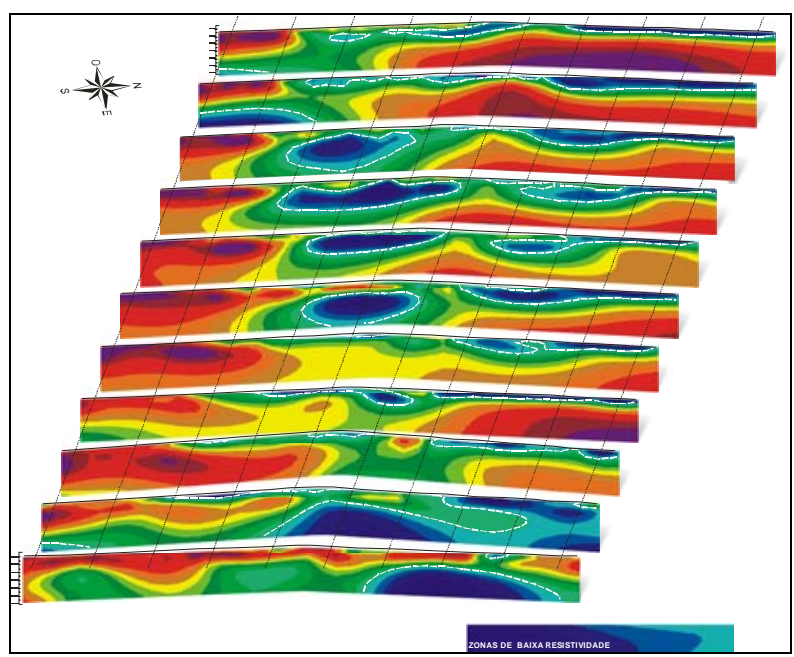

Figura 4: configuração tridimensional das regiões de baixa resistividade relativa - seções direcionadas $N$-S. 


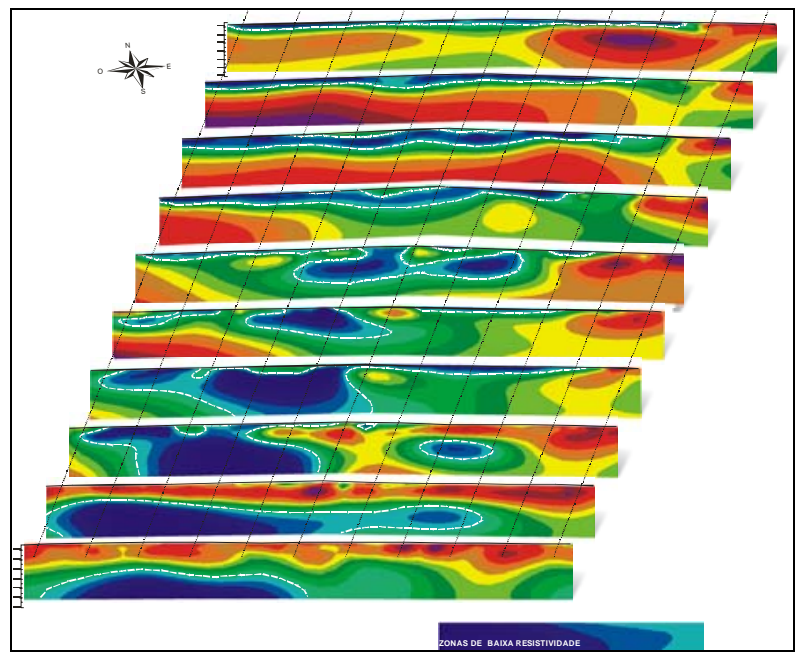

Figura 5: configuração tridimensional das regiões de baixa resistividade relativa - seções direcionadas $E-W$.

A geologia local, identificada na descrição das sondagens, apresenta um substrato caracterizado pela presença de um horizonte de aterro de até 6,0 metros, sobreposto ao gnaisse alterado. Foram descritos ainda horizontes caracterizados por uma areia extremamente fina, de coloração variando de cinza a negra, interpretados como o próprio catalisador.

Em relação à geoquímica, o tratamento dos resultados analíticos das amostras realizadas em conjunto com análises químicas do próprio catalisador, indicam a associação dos metais Ni (níquel) e Vn (vanádio) pode ser utilizada como guia indicativo para a presença do catalisador gasto.

\section{Discussão e Conclusões}

Com o auxílio da descrição das sondagens e dos dados de geoquímica sondagens locadas nas porções com anomalias de baixa resistividade, foram identificados horizontes com a presença física do catalisador gasto. As análises geoquímicas das amostras coletadas nessas porções apresentaram concentrações anômalas de níquel e vanádio. Estes horizontes, ou substratos, distribuem-se por toda a área investigada, dispostos desde camadas próximas à superfície $(0,5$ metro) até substratos mais profundos (9,0 metros). A Figura 5 apresenta a correlação entre estas regiões de baixa resistividade superficiais e a presença física do catalisador.

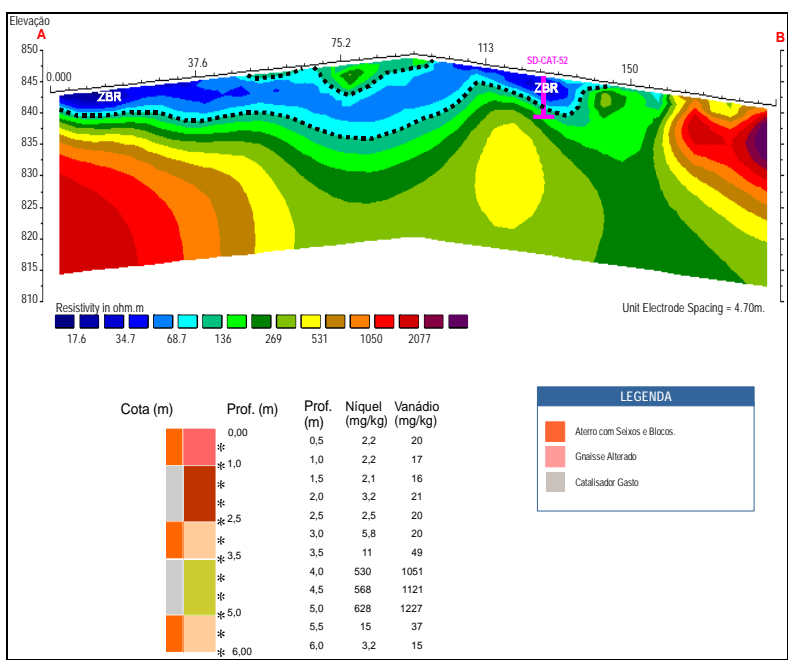

Figura 6: SEVME com anomalia de baixa resitividade superficial e correlação com a presença física de catalisador.

Dentre as sondagens executadas, não foi identificada na descrição geológica a presença do catalisador em profundidades superiores a 9,0 metros. As zonas de baixa resistividade (ZBR) em profundidades superiores a 10 metros (Figura 3) foram associadas a áreas de lixiviação dos elementos constituintes do catalisador gasto ( $\mathrm{Ni} \mathrm{e} \mathrm{V}$ ) sem que houvesse a presença física do catalisador. As amostras coletadas nessas regiões anomalas apresentaram concentrações desses elementos levemente alteradas em relação ao background local sem, entretanto, atingirem concentrações presentes nas amostras de catalisador gasto. A Figura 7 apresenta um exemplo desse caso.

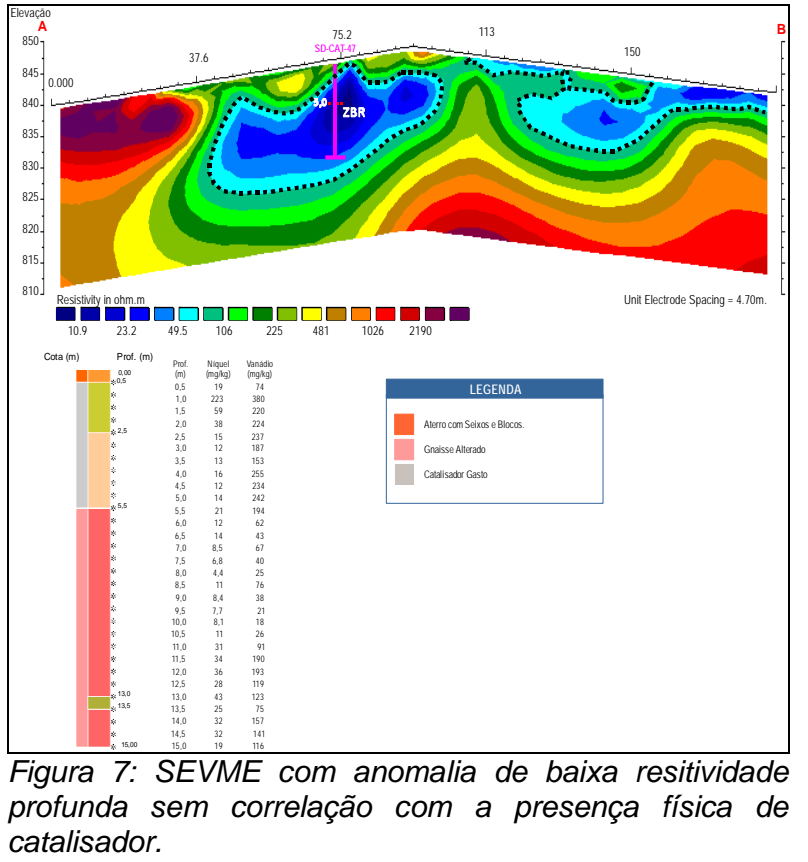


Conclui-se que a associação de dados geofísicos de eletroresistividade com dados diretos obtidos a partir da descrição de sondagens e análises geoquímicas, mostrase eficiente no mapeamento em subsuperfície para a determinação da presença de catalisador gasto e da lixiviação de metais para o solo.

\section{Agradecimentos}

À PETROBRAS - Petróleo Brasileiro S.A., pela disponibilização dos dados.

À Brain Tecnologia Ltda. pelo apoio e incentivo.

\section{Referências}

BRAIN 2000. Relatório de monitoramento ambiental. Técnicas GPR (2D e 3D) e tomografia elétrica associadas a análises químicas e controle por poços subterrâneos. Petrobras/REGAP, Relatório Interno. $16 p$ + figuras e anexos.

BRAIN 2005. Diagnóstico Geoambiental - Técnicas de Sondagem Elétrica Vertical Multieletrodos Associadas à Sondagens e Análises Geoquímicas. Petrobras/REGAP, Relatório Interno.

BRAIN 2006 - Relatório Diagnóstico Geoambiental Complementar. Petrobras/REGAP, Relatório Interno. 